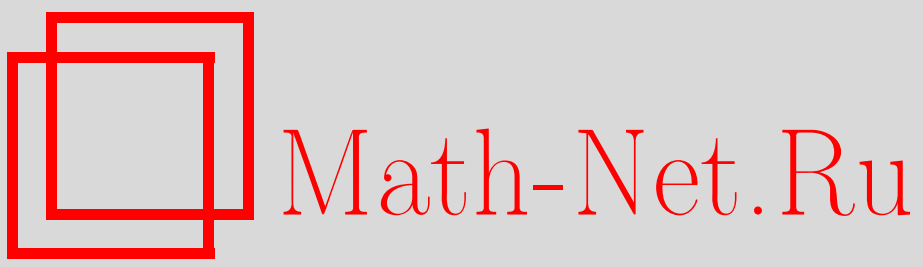

G. Peskir, A. N. Shiryaev, On the Brownian first-passage time over a one-sided stochastic boundary, Теория вероятн. и ее примен., 1997, том 42, выпуск 3, 591-602

DOI: https://doi.org/10.4213/tvp1956

Использование Общероссийского математического портала Math-Net.Ru подразумевает, что вы прочитали и согласны с пользовательским соглашением http://www.mathnet.ru/rus/agreement

Параметры загрузки:

IP : 35.174 .16 .151

26 апреля 2023 г., 15:01:44

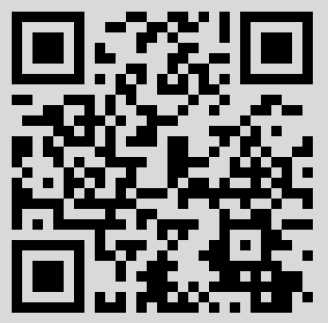


(C) $1997 \mathrm{r}$.

PEŠKIR G.* , SHIRYAEV A. N.** $^{* *}$

\section{ON THE BROWNIAN FIRST-PASSAGE TIME OVER A ONE-SIDED STOCHASTIC BOUNDARY}

Пусть $B=\left(B_{t}\right)_{t \geqslant 0}$ - стандартное броуновское движение относительно меры $\mathbf{P}$, выходящее из нуля; $S_{t}=\max _{0 \leqslant r \leqslant t} B_{r}-$ процесс максимума, связанный с $B ; g: \mathbf{R}_{+} \rightarrow \mathbf{R}-$ (строго) монотонная непрерывная функция, удовлетворяющая условию: $g(s)<s$ для всех $s \geqslant 0$. Пусть $\tau-$ момент первого достижения процессом $B$ гранипы $t \mapsto g\left(S_{t}\right):$

$$
\tau=\inf \left\{t>0 \mid B_{t} \leqslant g\left(S_{t}\right)\right\}
$$

Определим функцию $G$ как

$$
G(y)=\exp \left(-\int_{0}^{g^{-1}(y)} \frac{d s}{s-g(s)}\right)
$$

для $y \in \mathbf{R}$ из области изменения $g$. Тогда если $g$ возрастает, то

$$
\lim _{t \rightarrow \infty} \sqrt{t} \mathbf{P}\{\tau \geqslant t\}=\sqrt{\frac{2}{\pi}}\left(-g(0)-\int_{g(0)}^{g(\infty)} G(y) d y\right),
$$

и это число конечно. Аналогично, если $g$ убывает, то

$$
\lim _{t \rightarrow \infty} \sqrt{t} \mathbf{P}\{\tau \geqslant t\}=\sqrt{\frac{2}{\pi}}\left(-g(0)+\int_{g(\infty)}^{g(0)} G(y) d y\right)
$$

и это число может оказаться бесконечным. Эти результаты могут рассматриваться как обобщение на случай стохастических границ известных результатов о моменте первого достижения детерминированной границы. Метод доказательства опирается на классическую тауберову теорему и некоторые обобщения критериев НовиковаКазамаки для экспоненциальных мартингалов.

Ключевые слова и фразы: броуновское движение, момент первого достижения, случайная граниша, критерии Новикова-Казамаки, тауберова теорема, замена меры Гирсанова, локальный мартингал, диффузионный прощесс.

*Institute of Mathematics, University of Aarhus, Ny Munkegade, 8000 Aarhus, Denmark.

** Математический институт им. В. А. Стеклова РАН, ул. Губкина, 8, 117966 Москва, Россия. 
1. Introduction. In this paper we present the solution to the following problem. Let $B=\left(B_{t}\right)_{t \geqslant 0}$ be standard Brownian motion started at 0 under $\mathbf{P}$, let $S_{t}=\max _{0 \leqslant r \leqslant t} B_{r}$ be the maximum process associated with $B$, and let $g: \mathbf{R}_{+} \rightarrow \mathbf{R}$ be a (strictly) monotone continuous function satisfying $g(s)<s$ for all $s \geqslant 0$. Let $\tau$ be the first-passage-time of $B$ over the stochastic boundary $t \mapsto g\left(S_{t}\right)$ :

$$
\tau=\inf \left\{t>0 \mid B_{t} \leqslant g\left(S_{t}\right)\right\}
$$

(see Fig. 1 below). The problem we address is to compute the limit:

$$
\lim _{t \rightarrow \infty} \sqrt{t} \mathbf{P}\{\tau \geqslant t\}
$$

and to express it in terms of function $g$.

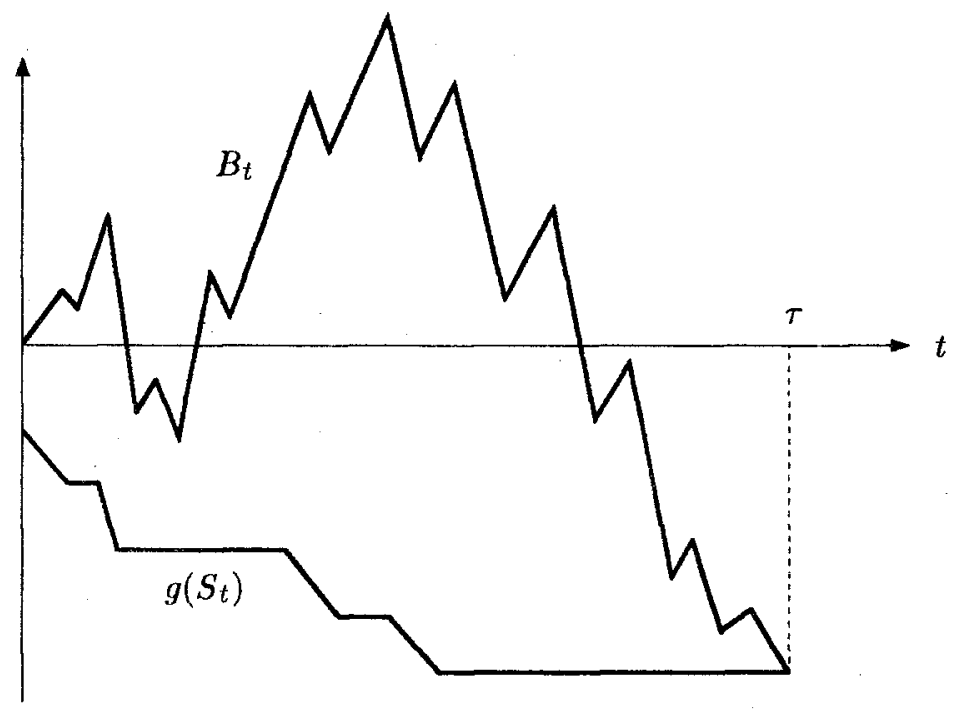

Fig. 1. A schematic drawing of the Brownian motion $B_{t}$ and the target process $g\left(S_{t}\right)$ with a decreasing function $s \mapsto g(s)$

If $g(s) \equiv g(0)<0$, it is well known that:

$$
\lim _{t \rightarrow \infty} \sqrt{t} \mathbf{P}\{\tau \geqslant t\}=\sqrt{\frac{2}{\pi}}(-g(0)) .
$$

A more general problem was recently treated by Novikov [7] for deterministic one-sided boundaries of the form $t \mapsto g(t)$. The main novelty in our approach is that we allow the boundary to be stochastic. It turns out that such a reformulation of the problem enables one to compute the limit in (1.2) explicitly. The solution is presented in Theorem 2.1 below. The proof is divided into several parts of independent interest. For simplicity we work 
with Brownian motion but the methods used in principle could be extended to treat similar problems for general one-dimensional time-homogeneous diffusions.

Stopping times of the form (1.1) have been investigated in the past. Instead of going into a historical exposition on this extensive subject, we shall rather refer the reader to the paper of Azéma and Yor [1] where such stopping times are used to obtain a simple solution to the Skorokhod problem. In [1] one also finds the Laplace transform of $\tau$, which (at least in principle) could lead to the explicit expression in (1.2). Such an approach, however, may have the drawback of computational complexity. In recent years stopping times of the form (1.1) gained a new attention by appearing as solutions to several optimal stopping problems [2], [5], [6], [9], [10].

The initial work on the problem above was motivated by the paper of Novikov [7]. From his work we learned about the useful role of the classical Tauberian theorem in such a context. At the same time we knew of the manuscript [3] where similar results were obtained for general continuous local martingales. While these general results could be used to handle the case above when $g$ is increasing, they are not directly applicable to the more difficult case when $g$ is decreasing. In this case we needed to use a refinement of the classical criteria for exponential martingales due to Novikov and Kazamaki (see [8, p. 317-319]). This refinement is in fact a new way of thinking of the exponential martingales which in essence relies on a simple Girsanov measure change.

2. The results and proofs. In this section we present the main result and proof. Before we state our main result, we want to make a few comments. Throughout we study the stopping time $\tau$ from (1.1). Given $p>0$, below we shall characterize when $\mathbf{E}\left(\tau^{p}\right)$ is finite (Corollary 2.1), and we shall compute $\mathbf{E}(\tau)$ (Corollary 2.2), both in terms of $g$. It is well known that in the context of one-sided boundaries the exponent $p=\frac{1}{2}$ plays a special role. To relate the problem about the limit in (1.2) with the integrability properties of $\tau$, the reader should note the following two facts which are easily verified by using standard arguments:

$$
\begin{gathered}
\limsup _{t \rightarrow \infty}(\sqrt{t} \mathbf{P}\{\tau \geqslant t\})<\infty \Longrightarrow \mathbf{E}\left(\tau^{1 / 2-\varepsilon}\right)<\infty \quad(\forall \varepsilon>0), \\
\mathbf{E}\left(\tau^{1 / 2}\right)<\infty \Longrightarrow \lim _{t \rightarrow \infty}(\sqrt{t} \mathbf{P}\{\tau \geqslant t\})=0 .
\end{gathered}
$$

The converse implications are not fulfilled in general. Our main result may be now stated as follows.

Theorem 2.1. Let $B=\left(B_{t}\right)_{t \geqslant 0}$ be standard Brownian motion started at 0 under $\mathbf{P}$, let $S_{t}=\max _{0 \leqslant r \leqslant t} B_{r}$ be the maximum process associated with $B$, and let $g: \mathbf{R}_{+} \rightarrow \mathbf{R}$ be a strictly monotone continuous function satisfying $g(s)<s$ for all $s \geqslant 0$. 
Let $\tau$ be the first-passage-time of $B$ over $t \mapsto g\left(S_{t}\right)$ :

$$
\tau=\inf \left\{t>0 \mid B_{t} \leqslant g\left(S_{t}\right)\right\}
$$

and let $G$ be the function defined by:

$$
G(y)=\exp \left(-\int_{0}^{g^{-1}(y)} \frac{d s}{s-g(s)}\right)
$$

for $y \in \mathbf{R}$ in the range of $g$.

If $g$ is increasing, then we have:

$$
\lim _{t \rightarrow \infty} \sqrt{t} \mathbf{P}\{\tau \geqslant t\}=\sqrt{\frac{2}{\pi}}\left(-g(0)-\int_{g(0)}^{g(\infty)} G(y) d y\right)
$$

and this number is finite.

If $g$ is decreasing, then we have:

$$
\lim _{t \rightarrow \infty} \sqrt{t} \mathbf{P}\{\tau \geqslant t\}=\sqrt{\frac{2}{\pi}}\left(-g(0)+\int_{g(\infty)}^{g(0)} G(y) d y\right)
$$

and this number may be infinite.

P r o o f. 1. In order to compute the limits in (2.5) and (2.6) we shall use a classical Tauberian (Abelian) theorem (see [4, p. 442-448]) which states that for any monotone $f: \mathbf{R}_{+} \rightarrow \mathbf{R}_{+}$we have:

$$
\lim _{\lambda \rightarrow 0}\left(\sqrt{\lambda} \int_{0}^{\infty} e^{-\lambda t} f(t) d t\right)=L \Longleftrightarrow \lim _{t \rightarrow \infty}(\sqrt{t} f(t))=\frac{L}{\sqrt{\pi}} .
$$

We shall use this result with $f(t)=\mathbf{P}\{\tau \geqslant t\}$. Then we have:

$$
\sqrt{\lambda} \int_{0}^{\infty} e^{-\lambda t} f(t) d t=\mathbf{E}\left(\frac{1-e^{-\lambda \tau}}{\sqrt{\lambda}}\right)
$$

for all $\lambda>0$. Hence we see that the problem reduces to compute the limit:

$$
\lim _{\lambda \rightarrow 0} \mathbf{E}\left(\frac{1-e^{-\lambda \tau}}{\sqrt{\lambda}}\right)
$$

2. To compute this limit, consider the local martingale:

$$
M_{t}=-B_{t \wedge \tau}
$$

and the exponential local martingale associated with it:

$$
\mathcal{E}_{\lambda}(M)_{t}=\exp \left(\lambda M_{t}-\frac{\lambda^{2}}{2}\langle M\rangle_{t}\right)
$$


where $\lambda>0$. It will be clear from our proof below that we may, and in the sequel do assume, that $\mathbf{P}\{\tau<\infty\}=1$. Then clearly $M_{\infty}:=\lim _{t \rightarrow \infty} M_{t}=$ $-B_{\tau}\left(\mathbf{P}\right.$-a.s.) and $\langle M\rangle_{\infty}:=\lim _{t \rightarrow \infty}\langle M\rangle_{t}=\tau<\infty$ (P-a.s.).

Suppose that $M_{\infty}$ is integrable, and that the following two conditions are satisfied:

$$
\begin{aligned}
\mathbf{E}\left(\mathcal{E}_{\lambda}(M)_{\infty}\right) & =1 \quad \text { for all } 0<\lambda<\lambda_{*} \\
\mathbf{E}\left(M_{\infty}^{+} \mathcal{E}_{\lambda}(M)_{\infty}\right) & \rightarrow \mathbf{E}\left(M_{\infty}^{+}\right) \quad \text { as } \quad \lambda \rightarrow 0
\end{aligned}
$$

with some $\lambda_{*}>0$. Then we claim that:

$$
\lim _{\lambda \rightarrow 0} \mathbf{E}\left(\frac{1-e^{-\lambda \tau}}{\sqrt{\lambda}}\right)=\sqrt{2} \mathbf{E}\left(M_{\infty}\right) .
$$

To prove (2.14) note that by (2.12) we have:

$$
\begin{aligned}
& \frac{1}{\lambda / \sqrt{2}} \mathbf{E}\left(1-\exp \left(-\frac{\lambda^{2}}{2}\langle M\rangle_{\infty}\right)\right) \\
& =\frac{\sqrt{2}}{\lambda} \mathbf{E}\left(\mathcal{E}_{\lambda}(M)_{\infty}-\exp \left(-\frac{\lambda^{2}}{2}\langle M\rangle_{\infty}\right)\right) \\
& \quad=\sqrt{2} \mathbf{E}\left(\left(\frac{\exp \left(\lambda M_{\infty}\right)-1}{\lambda}\right) \exp \left(-\frac{\lambda^{2}}{2}\langle M\rangle_{\infty}\right)\right)
\end{aligned}
$$

for all $0<\lambda<\lambda_{*}$. To proceed introduce the following notation:

$$
R_{\lambda}=\left(\frac{\exp \left(\lambda M_{\infty}\right)-1}{\lambda}\right) \exp \left(-\frac{\lambda^{2}}{2}\langle M\rangle_{\infty}\right)
$$

Then clearly $R_{\lambda} \rightarrow M_{\infty}$ as $\lambda \rightarrow 0$, and since $\mid e^{x}-1 \uparrow \leqslant x^{+} e^{x}+x^{-}$for all $x \in \mathbf{R}$, we have:

$$
\begin{aligned}
\left|R_{\lambda}\right| & \leqslant\left(M_{\infty}^{+} \exp \left(\lambda M_{\infty}\right)+M_{\infty}^{-}\right) \exp \left(-\frac{\lambda^{2}}{2}\langle M\rangle_{\infty}\right) \\
& \leqslant M_{\infty}^{+} \mathcal{E}_{\lambda}(M)_{\infty}+M_{\infty}^{-}
\end{aligned}
$$

for all $\lambda>0$. Now note that

$$
0 \leqslant M_{\infty}^{+} \mathcal{E}_{\lambda}(M)_{\infty} \longrightarrow M_{\infty}^{+} \quad \text { as } \quad \lambda \rightarrow 0,
$$

so the condition (2.13) is equivalent to the uniform integrability of $M_{\infty}^{+} \mathcal{E}_{\lambda}(M)_{\infty}$ for $\lambda \rightarrow 0$. Thus from (2.17) we see that $R_{\lambda}$ is uniformly integrable for $\lambda \rightarrow 0$, so by letting $\lambda \rightarrow 0$ in (2.15) we get (2.14).

3. The rest of the proof consists of two separate parts. The first part is to derive the distribution law of $M_{\infty}$, which will lead to a closed form expression for $\mathbf{E}\left(M_{\infty}\right)$ in (2.14). The second part is to verify that (2.12) and 
(2.13) are fulfilled whenever $M_{\infty}$ is integrable. Combining these two facts we will obtain (2.5) and (2.6).

To find the distribution law of $M_{\infty}$, recall that $M_{\infty}=-B_{\tau}=-g\left(S_{\tau}\right)$, so it will be sufficient to derive the distribution law of $S_{\tau}$. For this, we shall use the fact that the process:

$$
H\left(S_{t}\right)-\left(S_{t}-B_{t}\right) H^{\prime}\left(S_{t}\right)
$$

is a local martingale whenever $H \in C^{1}$ (see [1]). This is easily verified by Itô's formula and in essence relies upon the fact that $d S_{t}=0$ outside $X_{t}=S_{t}$ (see Fig. 2 below).

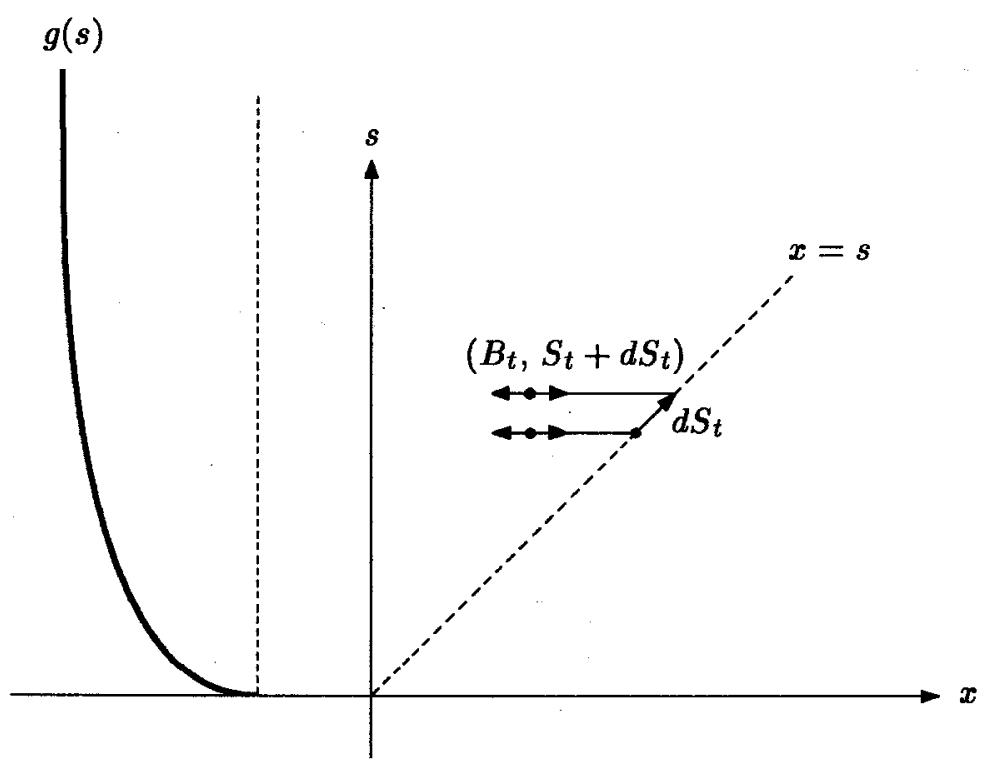

Fig. 2. A schematic drawing of the diffusion $\left(B_{t}, S_{t}\right)$ with a decreasing target function $s \mapsto g(s)$. The diffusion $\left(B_{t}, S_{t}\right)$ can increase in the second component (infinitesimally little) only after hitting the diagonal $x=s$

We shall apply this fact with

$$
H(s)=\int_{0}^{s} h(r) d r
$$

where $h: \mathbf{R}_{+} \rightarrow \mathbf{R}_{+}$is any continuous function which is zero at zero and outside a compact set. Then the process in (2.18) is, uniformly bounded and therefore it is a uniformly integrable martingale. Thus by the optional sampling theorem we get:

$$
\mathbf{E}\left(H\left(S_{\tau}\right)\right)=\mathbf{E}\left(\left(S_{\tau}-B_{\tau}\right) H^{\prime}\left(S_{\tau}\right)\right) .
$$


Integrating by parts, the left-hand side in (2.19) equals:

$$
\begin{aligned}
\mathbf{E}\left(H\left(S_{\tau}\right)\right) & =\int_{0}^{\infty} H(s) d F_{S_{\tau}}(s)=\left.H(s) F_{S_{\tau}}(s)\right|_{0} ^{\infty}-\int_{0}^{\infty} F_{S_{\tau}}(s) d H(s) \\
& =H(\infty)-\int_{0}^{\infty} F_{S_{\tau}}(s) d H(s)=\int_{0}^{\infty}\left(1-F_{S_{\tau}}(s)\right) h(s) d s .
\end{aligned}
$$

On the other hand, the right-hand side is equal to:

$$
\begin{aligned}
\mathbf{E}\left(\left(S_{\tau}-B_{\tau}\right) H^{\prime}\left(S_{\tau}\right)\right) & =\mathbf{E}\left(\left(S_{\tau}-g\left(S_{\tau}\right)\right) H^{\prime}\left(S_{\tau}\right)\right) \\
& =\int_{0}^{\infty}(s-g(s)) h(s) d F_{S_{\tau}}(s)
\end{aligned}
$$

Since this is true for all $h$ of the specified type, from (2.20) and (2.21) we find that:

$$
\frac{d F_{S_{\tau}}}{d s}(s)=\frac{1-F_{S_{\tau}}(s)}{s-g(s)}
$$

for $s>0$. The equation (2.22) is easily solved, and since $F_{S_{\tau}}(0)=0$, this leads to:

$$
F_{S_{\tau}}(s)=1-\exp \left(-\int_{0}^{s} \frac{d t}{t-g(t)}\right)
$$

for $s \geqslant 0$ (see [8, p. 258-264] and note in particular Exc. VI.5.9). The distribution law of $B_{\tau}=g\left(S_{\tau}\right)$ is now easily obtained from (2.23).

4. Having the distribution law of $B_{\tau}$, we can compute $\mathbf{E}\left(M_{\infty}\right)=$ $-\mathbf{E}\left(B_{\tau}\right)$ in (2.14). For this assume first that $g$ is increasing. Then by (2.23) the integration by parts gives:

$$
\begin{aligned}
\mathbf{E}\left(M_{\infty}\right) & =-\mathbf{E}\left(B_{\tau}\right)=-\left(g(0)+\int_{g(0)}^{g(\infty)} \mathbf{P}\left\{B_{\tau} \geqslant y\right\} d y\right) \\
& =-\left(g(0)+\int_{g(0)}^{g(\infty)} \mathbf{P}\left\{g\left(S_{\tau}\right) \geqslant y\right\} d y\right) \\
& =-\left(g(0)+\int_{g(0)}^{g(\infty)} \mathbf{P}\left\{S_{\tau} \geqslant g^{-1}(y)\right\} d y\right) \\
& =-\left(g(0)+\int_{g(0)}^{g(\infty)}\left(1-F_{S_{r}}\left(g^{-1}(y)\right)\right) d y\right) \\
& =-\left(g(0)+\int_{g(0)}^{g(\infty)} \exp \left(-\int_{0}^{g^{-1}(y)} \frac{d s}{s-g(s)}\right) d y\right)
\end{aligned}
$$

which together with (2.14) and (2.7) + (2.8) leads to (2.5) whenever conditions (2.12) and (2.13) are satisfied. If $g$ is decreasing, then similarly:

$$
\mathbf{E}\left(M_{\infty}\right)=-\mathbf{E}\left(B_{\tau}\right)=-\left(g(0)-\int_{g(\infty)}^{g(0)} \mathbf{P}\left\{B_{\tau} \leqslant y\right\} d y\right)
$$




$$
\begin{aligned}
& =-\left(g(0)-\int_{g(\infty)}^{g(0)} \mathbf{P}\left\{g\left(S_{\tau}\right) \leqslant y\right\} d y\right) \\
& =-\left(g(0)-\int_{g(\infty)}^{g(0)} \mathbf{P}\left\{S_{\tau} \geqslant g^{-1}(y)\right\} d y\right) \\
& =-\left(g(0)-\int_{g(\infty)}^{g(0)}\left(1-F_{S_{\tau}}\left(g^{-1}(y)\right)\right) d y\right) \\
& =-\left(g(0)-\int_{g(\infty)}^{g(0)} \exp \left(-\int_{0}^{g^{-1}(y)} \frac{d s}{s-g(s)}\right) d y\right)
\end{aligned}
$$

which together with (2.14) and (2.7) $+(2.8)$ leads to $(2.6)$, whenever $M_{\infty}$ is integrable, and conditions (2.12) and (2.13) are satisfied.

5. It should be noted that when $g$ is increasing (thus bounded from below) the random variable $M_{\infty}=-B_{\tau}$ is integrable, and we have $0 \leqslant$ $\mathbf{E}\left(M_{\infty}\right)<\infty$. This is easily seen by analyzing the final expression in (2.24). To see this in another way, note that $M=\left(M_{t}\right)_{t \geqslant 0}$ is uniformly bounded from above by a constant, so that $\left(M_{t}^{+}\right)_{t \geqslant 0}$ is uniformly integrable. Moreover, since $M$ is a continuous local martingale, there exists a sequence of (bounded) stopping times $\left\{\tau_{n} \mid n \geqslant 1\right\}$ such that $\tau_{n} \uparrow \infty$ and $\left(M_{t \wedge \tau_{n}}\right)_{t \geqslant 0}$ is a (bounded) martingale. By the martingale property and Fatou's lemma we may conclude $\mathbf{E}\left(M_{\infty}^{-}\right) \leqslant \lim _{t, n \rightarrow \infty} \mathbf{E}\left(M_{t \wedge \tau_{n}}^{-}\right)=\lim _{t, n \rightarrow \infty} \mathbf{E}\left(M_{t \wedge \tau_{n}}^{+}\right)=$ $\mathbf{E}\left(M_{\infty}^{+}\right)<\infty$.

If $g$ is decreasing, however, the random variable $M_{\infty}=-B_{\tau}$ may not be integrable. We do have though that $\mathbf{E}\left(M_{\infty}\right) \geqslant 0$ since $M_{\infty}$ is non-negative. A simple truncation argument (by applying the preceding observations to the functions $g_{n}(s)=g(s) \vee(-n)$ which are bounded from below and in the limit tend to $g$ as $n \rightarrow \infty)$ it is clear that the limit on the left-hand side in (2.6) will be equal $+\infty$ if $\mathbf{E}\left(M_{\infty}\right)=+\infty$. Thus to complete the proof it is enough to verify that conditions (2.12) and (2.13) are satisfied under the assumption that $M_{\infty}$ is integrable.

In either of the cases it should be observed that since $M_{\infty}=-B_{\tau}=$ $-g\left(S_{\tau}\right)$, the integrability of $M_{\infty}$ implies that $S_{\tau}<\infty$ (P-a.s.), and therefore we have $\mathbf{P}\{\tau<\infty\}=1$.

6. To show that conditions (2.12) and (2.13) are satisfied, assume first that $g$ is increasing. Then $M=\left(M_{t}\right)_{t \geqslant 0}$ is uniformly bounded from above by a constant, and therefore the exponential local martingale $\mathcal{E}_{\lambda}(M)=$ $\left(\mathcal{E}_{\lambda}(M)_{t}\right)_{t \geqslant 0}$ is uniformly integrable for all $\lambda>0$. Thus it is a martingale, and (2.12) is clearly satisfied. Moreover, since $M_{\infty}$ is also bounded from above by a constant, we see that $\left(M_{\infty}^{+} \mathcal{E}_{\lambda}(M)_{\infty}\right)_{\lambda>0}$ is uniformly integrable, so that (2.13) is clearly valid as well. This completes the proof of (2.5) when $g$ is increasing. 
Assume now that $g$ is decreasing. Consider the exponential martingale:

$$
Z_{t}=Z_{t}^{\lambda}=\exp \left(-\lambda B_{t}-\frac{\lambda^{2}}{2} t\right)
$$

for $\lambda>0$. Denote $\mathcal{F}_{t}=\sigma\left(B_{s} \mid s \leqslant t\right)$ for $t \geqslant 0$, and let $\mathcal{F}_{\infty}=\sigma\left(\cup_{t \geqslant 0} \mathcal{F}_{t}\right)$. Let $\widetilde{\mathbf{P}}=\widetilde{\mathbf{P}}^{\lambda}$ denote the probability measure on $\mathcal{F}_{\infty}$ determined by:

$$
d \widetilde{\mathbf{P}}_{t}=Z_{t} d \mathbf{P}_{t}
$$

where $\widetilde{\mathbf{P}}_{t}$ and $\mathbf{P}_{t}$ denote the restrictions of $\widetilde{\mathbf{P}}$ and $\mathbf{P}$ to $\mathcal{F}_{t}$ respectively. Then, under $\widetilde{\mathbf{P}}=\widetilde{\mathbf{P}}^{\lambda}$ with $\lambda>0$, the process $\widetilde{B}_{t}=\widetilde{B}_{t}^{\lambda}=B_{t}+\lambda t$ is a standard Brownian motion. Moreover, it is well known that (in the usual sense):

$$
\widetilde{\mathbf{E}}\left(V 1_{\{\tau<\infty\}}\right)=\mathbf{E}\left(V 1_{\{\tau<\infty\}} Z_{\tau}\right)
$$

whenever $V$ is $\mathcal{F}_{\tau}$-measurable. This with $V \equiv 1$ shows that:

$$
\mathbf{E}\left(Z_{\tau}\right)=1 \Leftrightarrow \tilde{\mathbf{P}}\{\tau<\infty\}=1
$$

Now note that in the notation of (2.12) above we have $Z_{\tau}=Z_{\tau}^{\lambda}=\mathcal{E}_{\lambda}(M)_{\infty}$. Thus (2.12) is equivalent to the fact that $\tau<\infty$ under $\widetilde{\mathbf{P}}=\widetilde{\mathbf{P}}^{\lambda}$ for all $0<\lambda<\lambda_{*}$. To verify this note that:

$$
\tau=\inf \left\{t>0 \mid \widetilde{B}_{t}-\lambda t \leqslant g\left(\max _{0 \leqslant r \leqslant t}\left(\widetilde{B}_{r}-\lambda r\right)\right)\right\} .
$$

Since $t \mapsto \max _{0 \leqslant r \leqslant t}\left(\widetilde{B}_{r}-\lambda r\right)$ is bounded from above $(\widetilde{\mathbf{P}}$-a.s. $)$, and moreover $\widetilde{B}_{t}-\lambda t \rightarrow-\infty(\widetilde{\mathbf{P}}$-a.s. $)$, we clearly see from $(2.30)$ that $\tau<\infty$ under $\widetilde{\mathbf{P}}=\widetilde{\mathbf{P}}^{\lambda}$ for all $\lambda>0$. Thus the condition (2.12) is fulfilled for all $\lambda>0$.

To show (2.13) note by (2.28) that:

$$
\mathbf{E}\left(M_{\infty}^{+} \mathcal{E}_{\lambda}(M)_{\infty}\right)=-\mathbf{E}\left(B_{\tau} Z_{\tau}\right)=-\tilde{\mathbf{E}}\left(B_{\tau}\right)
$$

Motivated by (2.30) introduce the stopping time:

$$
\tau_{\lambda}=\inf \left\{t>0 \mid B_{t}-\lambda t \leqslant g\left(\max _{0 \leqslant r \leqslant t}\left(B_{r}-\lambda r\right)\right)\right\}
$$

for $\lambda>0$. Then clearly:

$$
\begin{aligned}
\operatorname{Law}\left(\tau_{\lambda} \mid \mathbf{P}\right) & =\operatorname{Law}(\tau \mid \widetilde{\mathbf{P}}) \\
\operatorname{Law}\left(B_{\tau} \mid \widetilde{\mathbf{P}}\right) & =\operatorname{Law}\left(B_{\tau_{\lambda}}-\lambda \tau_{\lambda} \mid \mathbf{P}\right)
\end{aligned}
$$

since $B_{\tau}=\widetilde{B}_{\tau}-\lambda \tau$. From (2.31) by (2.34) we get:

$$
\mathbf{E}\left(M_{\infty}^{+} \mathcal{E}_{\lambda}(M)_{\infty}\right)=-\widetilde{\mathbf{E}}\left(B_{\tau}\right)=-\mathbf{E}\left(B_{\tau_{\lambda}}-\lambda \tau_{\lambda}\right)
$$


Now note that $\tau_{\lambda} \rightarrow \tau$ and $B_{\tau_{\lambda}}-\lambda \tau_{\lambda} \rightarrow B_{\tau}$ (both pointwise) when $\lambda \rightarrow 0$. Moreover, the sequence $\tau_{\lambda}$ is (pointwise) increasing for $\lambda \downarrow 0$. To see this, take $\lambda^{\prime}<\lambda$, then (since $g$ is decreasing) at $t=\tau_{\lambda^{\prime}}$ we have:

$$
B_{t}-\lambda t \leqslant B_{t}-\lambda^{\prime} t=g\left(\max _{0 \leqslant r \leqslant t}\left(B_{r}-\lambda^{\prime} r\right)\right) \leqslant g\left(\max _{0 \leqslant r \leqslant t}\left(B_{r}-\lambda r\right)\right),
$$

so we must have $\tau_{\lambda} \leqslant \tau_{\lambda^{\prime}}$. Similarly, the sequence $B_{\tau_{\lambda}}-\lambda \tau_{\lambda}$ is (pointwise) decreasing for $\lambda \downarrow 0$. To see this, recall that:

$$
B_{\tau_{\lambda}}-\lambda \tau_{\lambda}=g\left(\max _{0 \leqslant r \leqslant \tau_{\lambda}}\left(B_{r}-\lambda r\right)\right) .
$$

Hence, since $\tau_{\lambda}$ is increasing, the maximum on the right-hand side is increasing for $\lambda \downarrow 0$, and the claim follows from the fact that $g$ is decreasing. It remains to apply the monotone convergence theorem in (2.35) to conclude:

$$
\lim _{\lambda \rightarrow 0} \mathbf{E}\left(M_{\infty}^{+} \mathcal{E}_{\lambda}(M)_{\infty}\right)=\lim _{\lambda \rightarrow 0} \mathbf{E}\left(-B_{\tau_{\lambda}}+\lambda \tau_{\lambda}\right)=\mathbf{E}\left(-B_{\tau}\right)=\mathbf{E}\left(M_{\infty}^{+}\right)
$$

This establishes (2.13) in the case $g$ is decreasing, and the proof of the theorem is complete.

$\mathrm{R} \mathrm{e} \mathrm{m} \mathrm{a} \mathrm{r} \mathrm{k} \mathrm{1.} \mathrm{In} \mathrm{the} \mathrm{proof} \mathrm{above} \mathrm{we} \mathrm{consider} \mathrm{strictly} \mathrm{monotone} g$ for simplicity. The proof can be generalized to treat more general functions $g$ at the expense of technical complexity. A similar remark may be directed to the underlying Brownian motion process. We feel that the proof could be extended to treat similar problems for general one-dimensional time-homogeneous diffusions (or even for certain discontinuous processes like Lévy's processes for instance).

R e m a r k 2. Note that taking $g_{n}(s)=g(0)+s / n$ in (2.5) and letting $n \rightarrow \infty$, in the limit we obtain (1.3). A similar approximation procedure can be applied in (2.6). There one should rather use $g_{n}(s)=g(0)-\sqrt{s} / n$, since the right-hand side in (2.6) may be infinite for «too small» $g$. To experience the right size for $g$, note that if $g(s)=g(0)-s^{\gamma}$ with $\gamma>0$, then the right-hand side in (2.6) is finite if and only if $0<\gamma<1$. Moreover, if $g(s)=g(0)-\varepsilon s^{\gamma}$ for some $\varepsilon>0$, then the right-hand side in (2.6) is infinite no matter how small $\varepsilon$ is. These facts are easily obtained by analyzing the integral in (2.6). To conclude we may summarize that the functions $g$ for which the limit in (2.6) is finite are of the form $g(s)=O\left(s^{\gamma}\right)$ for some $0<\gamma<1$.

Corollary 2.1. Let $B=\left(B_{t}\right)_{t \geqslant 0}$ be standard Brownian motion started at 0 under $\mathbf{P}$, let $S_{t}=\max _{0 \leqslant r \leqslant t} B_{r}$ be the maximum process associated with $B$, and let $g: \mathbf{R}_{+} \rightarrow \mathbf{R}$ be a strictly monotone continuous function satisfying $g(s)<s$ for all $s \geqslant 0$.

Let $\tau$ be the first-passage-time of $B$ over $t \mapsto g\left(S_{t}\right)$ :

$$
\tau=\inf \left\{t>0 \mid B_{t} \leqslant g\left(S_{t}\right)\right\}
$$


and let $p>0$ be given and fixed.

If $g$ is increasing, then $\mathbf{E}\left(\tau^{p}\right)<\infty$ if and only if:

$$
\int_{0}^{\infty} y^{2 p-1} \exp \left(-\int_{0}^{y} \frac{d s}{s-g(s)}\right) d y<\infty .
$$

If $g$ is decreasing, then $\mathbf{E}\left(\tau^{p}\right)<\infty$ if and only if (2.40) holds and:

$$
\int_{-g(0)}^{-g(\infty)} y^{2 p-1} \exp \left(-\int_{0}^{g^{-1}(-y)} \frac{d s}{s-g(s)}\right) d y<\infty .
$$

$\mathrm{P}$ r o of. By the Burkholder-Davis-Gundy inequality we know that $\mathbf{E}\left(\tau^{p}\right)<\infty$ if and only if

$$
\mathbf{E}\left(\max _{0 \leqslant t \leqslant \tau}\left|B_{t}\right|^{2 p}\right)<\infty
$$

If $g$ is increasing, the latter condition is clearly equivalent to $\mathbf{E}\left(S_{\tau}\right)^{2 p}<$ $\infty$, which is by (2.23) expressed as in (2.40). If $g$ is decreasing, the latter condition is clearly equivalent to both $\mathbf{E}\left(S_{\tau}\right)^{2 p}<\infty$ and $\mathbf{E}\left(-B_{\tau}\right)^{2 p}=$ $\mathrm{E}\left(-g\left(S_{\tau}\right)\right)^{2 p}<\infty$, which is again by (2.23) expressed as in (2.40) and (2.41). This completes the proof.

We shall conclude our exposition by indicating how one can compute the expectation of $\tau$ from (1.1) in a simple way when the underlying Brownian motion process starts at any point.

Corollary 2.2. Suppose we are given a standard Brownian motion $B=$ $\left(B_{t}\right)_{t \geqslant 0}$ started at some $x \geqslant 0$ under $\mathbf{P}_{x}$. Let $S_{t}=\max _{0 \leqslant r \leqslant t} B_{r}$ be the maximum process associated with $B$, and let $g: \mathbf{R}_{+} \rightarrow \mathbf{R}$ be a (strictly) increasing continuous function satisfying $g(s)<s$ for all $s \geqslant 0$. Let $\tau$ be the first-passage-time of $B$ over $t \mapsto g\left(S_{t}\right)$ :

$$
\tau=\inf \left\{t>0 \mid B_{t} \leqslant g\left(S_{t}\right)\right\} .
$$

Then the following formula is valid:

$$
\mathbf{E}_{x}(\tau)=\int_{x}^{\infty} \frac{(x-g(t))^{2}}{t-g(t)} \exp \left(-\int_{x}^{t} \frac{d s}{s-g(s)}\right) d t
$$

whenever $\mathbf{E}_{x}(\tau)$ is finite, i.e., the condition (2.40) holds.

$\mathrm{P}$ r o of. By a standard argument it is enough to prove (2.43) when the integral on the right-hand side is finite. Then $\left(B_{t}-x\right)_{t \geqslant 0}$ is a standard Brownian motion started at 0 under $\mathbf{P}_{x}$, and clearly:

$$
\mathbf{E}_{x}(\tau)=\mathbf{E}_{x}\left|B_{\tau}-x\right|^{2}=\mathbf{E}_{0}\left|B_{\tau}\right|^{2}=\mathbf{E}_{0}\left|h\left(S_{\tau}\right)\right|^{2}
$$

where $h(s)=g(s+x)-x$. The distribution law of $S_{\tau}$ is then given by (2.23) where $g$ is to be replaced by $h$. This easily leads to the formula (2.43) and completes the proof. 


\section{REFERENCES}

1. Azéma J., Yor M. Une solution simple au problème de Skorokhod. - Lecture Notes in Math., 1979, v. 721 , p. 90-115, p. 625-633.

2. Дубияс Л. E., IIепn J. А., Ширнев А. Н. Оптимальные правила остановки и максимальные неравенства для процессов Бесселя. - Теория вероятн. и ее примен.; 1993, т. 38, в. 2, с. 288-330.

3. Elworthy $K . L$., $L i X . M$., Yor $M$. On the tails of the supremum and the quadratic variation of strictly local martingales. - Lecture Notes in Math., 1997, v. 1655, p. $120-133$.

4. Feller W. An introduction to probability theory and its applications. 2nd ed. New York: Wiley, 1971.

5. Graversen S. E.; Peskir G. On Doob's maximal inequality for Brownian motion. Research Report № 337. Aarhus: Dept. Theoret. Statist., 1995. (To appear in Stochastic Process. Appl.)

6. Graversen S. E., Peskir G. Optimal stopping in the $L \log L$-inequality of Hardy and Littlewood. Research Report. № 360. Aarhus: Dept. Theoret. Statist., 1996. (To appear in J. London Math. Soc.)

7. Новиков $A$. A. Мартингалы, тауберова теорема и стратегии азартных игр. Теория вероятн. и ее примен., 1996, т. 41, в. 4, с. 810-826.

8. Revuz D., Yor M. Continuous Martingales and Brownian Motion. Berlin-Heidelberg: Springer-Verlag, 1994.

9. Shepp L. A., Shiryaev A. N. The Russian option: Reduced regret. - Ann. Appl. Probab., 1993, v. 3, p. 631-640.

10. IIIияев $A$ : H. Минимаксная оптимальность метода кумулятивных сумм (CUSUM) в случае непрерывного времени. - Успехи матем. наук, 1996, т. 51, № 4, c. 173-174. 